\title{
RÉMI JIMENES, Charlotte Guillard. Une femme imprimeur à la Renaissance
}

\section{Maria Grazia Dalai}

\section{(2) OpenEdition}

\section{Journals}

\section{Edizione digitale}

URL: http://journals.openedition.org/studifrancesi/16041

DOI: 10.4000/studifrancesi. 16041

ISSN: 2421-5856

\section{Editore}

Rosenberg \& Sellier

\section{Edizione cartacea}

Data di pubblicazione: 1 décembre 2018

Paginazione: 484-485

ISSN: 0039-2944

\section{Notizia bibliografica digitale}

Maria Grazia Dalai, «RÉMı JIMENEs, Charlotte Guillard. Une femme imprimeur à la Renaissance», Studi Francesi [Online], 186 (LXII | III) | 2018, online dal 01 janvier 2019, consultato il 11 janvier 2021. URL: http://journals.openedition.org/studifrancesi/16041 ; DOI: https://doi.org/10.4000/studifrancesi. 16041

Questo documento è stato generato automaticamente il 11 janvier 2021.

\section{(c) (i) (9)}

Studi Francesi è distribuita con Licenza Creative Commons Attribuzione - Non commerciale - Non opere derivate 4.0 Internazionale. 


\title{
RÉMI JIMENES, Charlotte Guillard. Une femme imprimeur à la Renaissance
}

\author{
Maria Grazia Dalai
}

\section{NOTIZIA}

RÉMI JIMENES, Charlotte Guillard. Une femme imprimeur à la Renaissance. Préface de Roger Chartier, Tours, Presses universitaires François Rabelais de Tours / Rennes, Presses universitaires de Rennes, 2017, «Renaissance», 303 pp.

1 Il libro di Rémi Jimenes, tratto dalla sua tesi di dottorato discussa a Tours nel 2014, è dedicato alla figura della stampatrice Charlotte Guillard che svolse la propria attività a Parigi nella prima metà del XVI secolo. Attraverso lo studio di numerosi documenti d'archivio, l'autore ripercorre le tappe principali della vita di questa tipografa: Charlotte, originaria della regione del Maine, fece parte di una famiglia della media borghesia. Entrò nel mondo della tipografia intorno al 1507 quando sposò a Parigi lo stampatore alsaziano Berthold Rembolt che aveva fondato la bottega all'insegna del "Soleil d'Or". Rimasta vedova, si risposò nel 1520 con il libraio Claude Chevallon. Entrambi i mariti orientarono la politica editoriale dell'atelier: Rembolt si specializzò nella produzione di edizioni giuridiche, Chevallon si dedicò alla stampa delle opere dei Padri della Chiesa. Nel 1537, alla morte del secondo marito, Charlotte prese la conduzione della stamperia.

2 Il volume si focalizza, in particolare, sulla storia di questa importante figura femminile che diresse fra il 1537-1557, una della più prestigiose imprese tipografiche parigine. In circa vent'anni la tipografa pubblicò 181 edizioni, fra cui l'opera omnia in dieci volumi di Sant'Agostino, pubblicata nel 1541, e l'edizione di San Gerolamo, data alle stampe nel 1546. Charlotte Guillard diresse la propria impresa anche grazie al sostegno dei nipoti, come è attestato dal numero di edizioni condivise che la vedova pubblicò in associazione con alcuni di essi, in particolare con Guillaume Desboys e Sébastien Nivelle. Alla morte di Charlotte, i due nipoti proseguirono la sua politica editoriale con 
la pubblicazione di numerose opere dei Padri della Chiesa e di varie edizioni giuridiche. Nel 1582 fondarono la famosa Compagnia dei tipografi di Parigi detta "Compagnie de la Grand-Navire". Charlotte Guillard pose così le basi di quella che sarà una delle associazioni più importanti dell'edizione europea degli inizi del xvII secolo. Per quanto riguarda la stampa delle opere dei Padri della Chiesa Guillard si servì del contributo di insigni teologi legati al Collegio di Navarra: Louis Lasseré, Jean de Gagny, Jean Benoît, Godefroy Tilmann. Anche per i testi giuridici e per le opere di medicina si avvalse della collaborazione di esperti studiosi che appartenevano al Collegio della Sorbona. Vi furono inoltre quattro personaggi che ebbero un ruolo chiave nell'attività dell'atelier: il correttore di bozze Louis Miré, il traduttore Jacques de Vintimille, l'ecclesiastico Jean $\mathrm{Du}$ Tillet e il magistrato Aymar de Ranconnet. Come scrive Rémi Jimenes «le programme du Soleil d'Or apparaît ainsi comme le produit d'une intelligence collective, définie non par l'intention d'un concepteur unique, mais par l'incessant dialogue des savants avec les typographes» (p. 229). Inoltre nell'atelier si incontravano numerosi personaggi che collaboravano malgrado posizioni intellettuali e ideologiche a volte divergenti. Il periodo in cui opera Guillard non è ancora quello delle fratture irrimediabili tra protestanti e cattolici o tra umanisti e teologi. I collaboratori del "Soleil d'Or" trovano un terreno d'intesa nella riscoperta e nella stampa delle fonti antiche. L'interesse filologico comune permette così di ignorare le querelles dogmatiche. Questo studio conferma infatti la collaborazione e frequentazione negli anni 1540 fra cattolici e protestanti. La società parigina di questo decennio non è - come noto - né quella della Saint-Barthélemy né quella della Ligue. Charlotte Guillard appartiene ancora al beau seizième siècle entusiasta e ottimista. Morendo nel 1557, non conoscerà le lotte religiose che insanguineranno la Francia alcuni anni più tardi.

3 L'A., dopo questa corposa parte del suo volume, dedica successivamente diverse pagine allo studio dei caratteri utilizzati da Charlotte Guillard che, a partire dalla seconda metà degli anni 1540, abbandona l'uso delle lettere gotiche a favore di quelle corsive, queste ultime disegnate da Granjon e da Haultin. Anche il materiale decorativo (come la marca editoriale e le lettere ornate) subisce dei cambiamenti che testimoniano dell'apertura dell'atelier alle novità del tempo. Interessanti sono poi le pagine dedicate alla collaborazione che Charlotte intrattenne negli anni 1540-1551 con l'editore lionese Hugues de La Porte. Quest'ultimo stampò, per conto dell'editrice parigina, varie edizioni dei Padri della Chiesa: le opere di Sant'Agostino (1541), San Giovanni Crisostomo (1543), Tertulliano (1545), San Bernardo di Chiaravalle (1547, 1551), Sant'Ambrogio (1550). Hugues de La Porte si servì delle competenze che l'atelier aveva maturato con la pubblicazione delle opere dei Padri della Chiesa, mentre Charlotte Guillard poté beneficiare dell'apporto finanziario dell'editore lionese che le permise di dare alla stampa opere così monumentali e, pertanto, impegnative a livello di costi. Inoltre, la collaborazione con Hugues de La Porte consentì a Charlotte Guillard di conquistare nuovi mercati (in modo particolare quello spagnolo), grazie alle reti di distribuzione della filiera lionese.

Il volume di Rémi Jimenes è corredato da due appendici: nella prima troviamo i testamenti di Charlotte Guillard, di Louis Lasseré e di Louis Miré; nella seconda sono raccolti invece numerosi documenti d'archivio relativi a Guillard e ai suoi collaboratori. Il libro si conclude con gli annali delle edizioni di questa stampatrice (pp. 251-280) e con una nutrita bibliografia (pp. 285-303). Si tratta di uno studio importante, perché oltre ai numerosi dati forniti questo saggio è costruito intorno a una figura femminile di grandi competenze all'interno della realtà tipografica del tempo. Si tratta dunque di 
uno studio accurato, dotato di un bellissimo apparato iconografico, che aggiunge un nuovo e rilevante tassello agli studi sulle donne stampatrici dell'editoria francese ed europea nella prima metà del Cinquecento. 